\title{
PENGARUH SISTEM MANAJEMEN KESEHATAN DAN KESELAMATAN KERJA TERHADAP PRODUKTIVITAS KERJA KARYAWAN PT. MARUKI INTERNASIONAL INDONESIA
}

\author{
Faradillah Ramadhany ${ }^{1}$, Yahya Thamrin ${ }^{2}$, Arman $^{3}$ \\ ${ }^{1}$ Universitas Muslim Indonesia \\ ${ }^{2}$ Universitas Muslim Indonesia \\ ${ }^{3}$ Universitas Muslim Indonesia
}

Alamat korespondensi : (dilsramadhany@gmail.com/08114449901)

\begin{abstract}
ABSTRAK
Produktivitas tenaga kerja dipengaruhi oleh berbagai faktor salah satunya adalah tingkat pemenuhan kebutuhan akan rasa aman, keselamatan (safety) dan kesehatan yang diberikan perusahaan kepada karyawannya. Peningkatan produktivitas tidak akan tercapai jika dalam proses kerjanya terjadi kecelakaan atau kerusakan yang dapat mengakibatkan kualitas menurun dan kapasitas produksi tidak tercapai. Tujuan penelitian ini adalah diketahuinya pengaruh manajemen kesehatan dan keselamatan kerja terhadap produktivitas kerja karyawan PT. Maruki Internasional Indonesia.Desain penelitian yang digunakan dalam penelitian ini adalah Observasional Analitik dengan pendekatan Cross Sectional Study.Jumlah sampel dalam penelitian ini adalah 84 responden dengan teknik pengambilan sampel purposive sampling.Variabel independen yaitu komitmen dan kebijakan K3, pelaksanaan K3, sedangkan variabel dependen yaitu produktivitas kerja.Data yang diperoleh dari responden dengan menggunakan kuesioner. Analisa data menggunakan Regresi Logistik dengan tingkat kemaknaan $\alpha=0,05$. Hasil analisis data berdasarkan Regresi Logistik diperoleh nilai komitmen dan kebijakan K3 terhadap produktivitas kerja yaitu $p=0,000<0,05$, pelaksanaan K3 terhadap produktivitas kerja yaitu $p=0,000<0,05$, yang dapat disimpulkan bahwa dari hasil analisis multivariat pelaksanaan K3 merupakan variabel yang paling berpengaruh terhadap produktivitas kerja karyawan PT. Maruki Internasional Indonesia dengan nilai OR $\operatorname{Exp(B)~6,424.Saran~}$ saya sebagai peneliti sebaiknya pihak perusahaan PT. Maruki Internasional Indonesia lebih memperhatikan sistem manajemen kesehatan dan keselamatan perusahaan untuk meningkatkan produktivitas kerja karyawan.
\end{abstract}

Kata Kunci : Sistem Manajemen K3, Komitmen dan Kebijakan K3, Pelaksanaan K3 dan Produktivitas Kerja

\section{PENDAHULUAN}

Sistem manajemen K3 merupakan konseppengelolaan K3 secara sistematis dankomprehensif dalam suatu sistemmanajemen yang utuh melalui proses perencanaan, penerapan, pengukuran, danpengawasan. Keselamatan dan kesehatan kerja berperan menjamin keamanan proses produksisehingga produktivitasnya dapat tercapai.(Ramli, 2013).

Secara global, ILO memperkirakan sekitar 337 juta kecelakaan kerja terjadi setiaptahunnya yang mengakibatkan 2,3 juta pekerja kehilangan nyawa. Sementara itu,data PT Jaminan Sosial Tenaga Kerja (Jamsostek) menunjukkan bahwa sekitar 0,7persen pekerja Indonesia mengalami kecelakaan kerja.

Data dari BPJS (2016), menyatakan bahwa angka kecelakaan kerja di Indonesia masih tinggi.Mengutip data Badan Penyelenggara Jaminan Sosial (BPJS) Ketenagakerjaan, hingga akhir 2015 telah terjadi kecelakaan kerja sebanyak 105.182
kasus.Sementara itu, untuk kasus kecelakaan berat yang mengakibatkan kematian tercatat sebanyak 2.375 kasus dari jumlah kecelakaan kerja.Data dari BPJS (2017), menyatakan bahwa angka kecelakaan kerja dari tahun 2016 hingga 2017 meningkat 20\%.Ada sebanyak 125.000 kasus kecelakaan kerja.

Dinas Tenaga Kerja Makassar pada tahun 2016 telah berhasil melampaui target penurunan jumlah kecelakaan kerja yang direalisasikan sebesar $8,57 \%$ dari target $5 \%$ dengan presentase capaian sebesar $171,43 \%$. Dari jumlah kecelakaan kerja pada tahun 2015 sebanyak 35 kasus mengalami penurunan pada tahun 2016 menjadi 32 kasus (Ketenagakerjaan, 2018).

Berdasarkan data yang diperoleh di PT. Maruki Internasional Indonesia menunjukan bahwa jumlah seluruh karyawan adalah sebanyak 250 orang yang terdiri dari 174 orang laki-laki dan 76 orang perempuan.

Data sekunder yang diperoleh dari klinik perusahaan PT. Maruki International 
Indonesia menunjukan bahwa penerapan Manajemen K3 belum mencapai Zero Accident.Hal dapat dilihat dari laporan kasus kecelakaan kerja. Pada tahun 2014 terdapat 21 kasus kecelakaan kerja, pada tahun 2015 terdapat 20 kasus kecelakaan kerja, pada tahun 2016 terdapat 10 kasus kecelakaan kerja serta pada tahun 2017 terdapat 12 kasus kecelakaan kerja.

Berdasarkan latar belakang diatas, maka peneliti tertarik melakukan penelitian tentang pengaruh sistem manajemen kesehatan dan keselamatan kerja terhadap produktivitas kerja karyawan PT. Maruki Internasional Indonesia.

\section{BAHAN DAN METODE}

\section{Lokasi, Populasi, Sampel}

Penelitian ini dilakukan di PT. Maruki Internasional Indonesia pada bulan Oktober 2018.Populasi pada penelitian ini adalah semua semua karyawan factory 1,2 , dan 3 di PT. Maruki Internasional Indonesia.Jumlah populasi pada tahun 2018 sebanyak 106 karyawan di PT. Maruki Internasional Indonesia.Teknik pengambilan sampel pada penelitian ini menggunakan purposive sampling sebanyak 84 orang dengan menggunakan rumus slovin

1. kriteria inklusi:
a. Bersedia menjadi responden.
b. Masa kerja minimal 1 tahun.
c. Mampu membaca dan menulis

2. kriteria eksklusi:
a. Karyawan yang sedang dalam keadaan sakit atau cuti
b. Responden tidak hadir saat penelitian dilakukan.

\section{Pengumpulan Data}

1. Data Primer

Pengambilan data primer dilakukan dengan observasi lingkungan kerja dan hasil koesioner.

2. Data Sekunder

Data sekunder dalam penelitian ini diperoleh dari PT. Maruki Internasional Indonesia dengan cara studi dokumen. Data sekunder meliputi gambaran umum lokasi penelitian, jumlah tenaga kerja, dan pembagian jam kerja.

\section{Pengolahan Data}

1. Editing

Editing merupakan kegiatan yang dilakukan setelah kuesioner dikumpulkan kembali dari responden untuk melakukan pemeriksaan kelengkapan data, kejelasan dan konsistensi jawaban.

\section{Coding}

Coding merupakan tahapan untuk pemberian kode pada setiap jawaban, kemudian diklasifikasikan dalam kelompokkelompok dengan kode yang sama.

3. Entry Data

Setelah data lengkap dan diberi kode maka kemudian data diproses agar bisa dianalisis. Proses ini dilakukan dengan memasukkan data dari kuesioner ke dalam program computer SPSS 17.

4. Cleaning

Pada tahap ini setelah semua data darikuesioner di-entry, kemudian dicek kembali untuk mengetahui adanya kesalahan yang mungkin terjadi ketika proses meng-entry data dan selanjutnya dilakukan koreksi.

\section{Analisis Data}

1. Analisis Univariat

Analisis ini digunakan terhadap tiap variabel dari hasil penelitian pada umumnya dalam analisis ini hanya menghasilkan distribusi dan presentase dari tiap variabel.Data hasil penelitian ini dideskripsikan dalam bentuk tabel, grafik dan narasi.Untuk mengevaluasi besarnya proporsi masing-masing faktor yang meningkatkan resiko yang ditemukan untuk masing-masing variabel yang diteliti.Analisis univariat bermanfaat untuk melihat apakah data sudah layak untuk dilakukan analisis, melihat gambaran data yang dikumpulkan dan apakah data sudah optimal untuk analisis lebih lanjut.

2. Analisis Bivariat

Analisis bivariat dalam penelitian ini digunakan untuk mencari hubungan antara variabel bebas dan variabel terikat dengan uji statistik yang disesuaikan dengan skala data yang ada.Uji statistik yang digunakan adalah regresi logistik.

3. Analisis Multivariat

Analisis bivariat hanya akan menghasilkan hubungan antara dua variable yang bersangkutan (variable independen dan variable dependen). Untuk mengetahui hubungan lebih dari satu variable dependen, maka harus dilanjutkan dengan melakukan analisis multivariate. Uji statistiik yang biasa digunakan yaitu uji regresi,logistic dimana nilai $p<0,25$ untuk mengetahui variabel independen yang mana yang lebih erat hubungannya dengan variabel dependen. 
HASIL PENELITIAN

1. Analisis Univariat

Tabel 1 Distribusi Responden Berdasarkan Karakteristik Responden Di PT. Maruki Internasional Indonesia Tahun 2018

\begin{tabular}{|c|c|c|}
\hline $\begin{array}{c}\text { Karakteristik } \\
\text { Responden }\end{array}$ & $\mathrm{n}$ & Presentase \\
\hline Umur \\
\hline 20-35 tahun & 46 & 54,8 \\
\hline 36-50 tahun & 38 & 45,2 \\
\hline Tingkat Pendidikan \\
\hline SMP & 8 & 9,5 \\
\hline SMA & 56 & 66,7 \\
\hline D3 & 14 & 16,7 \\
\hline S1 & 6 & 7,1 \\
\hline Masa Kerja & \multicolumn{3}{|l|}{} \\
\hline$<5$ tahun & 46 & 54,8 \\
\hline$\geq 5$ tahun & 23 & 27,4 \\
\hline
\end{tabular}

Berdasarkan data tabel 1, responden lebih banyak responden yang berada pada rentang usia 20-35 tahun, yaitu sebanyak 46 orang $(54,8 \%)$, yang berusia antara 36 50 tahun yaitu sebanyak 38 orang $(45,2 \%)$. Berdasarkan tingkat pendidikan yang paling banyak adalah pendidikan SMA, yaitu dengan jumlah 56 orang $(66,7 \%)$, dan yang paling kurang adalah pendidikan S1, yaitu sebanyak 6 orang $(7,1 \%)$. Berdasarkan masa kerjaResponden paling banyak masa kerja $<5$ tahun yang berjumlah 46 orang $(54,8 \%)$, responden yang masa kerja $\geq 5$ tahun berjumlah 23 orang $(27,4 \%)$.

2. Analisis Bivariat

Tabel 2 Hubungan Komitmen dan Kebijakan K3 Dengan Produktivitas Kerja Karyawan PT. Maruki Internasional Indonesia

\begin{tabular}{|c|c|c|c|c|c|c|}
\hline \multirow{3}{*}{$\begin{array}{c}\text { Komitmen } \\
\text { dan } \\
\text { Kebijakan } \\
\text { K3 }\end{array}$} & \multicolumn{4}{|c|}{ Produkytivitas Kerja } & \multirow{2}{*}{\multicolumn{2}{|c|}{ Total }} \\
\hline & \multicolumn{2}{|c|}{ Baik } & \multicolumn{2}{|c|}{ Kurang } & & \\
\hline & $\mathrm{n}$ & $\%$ & $\mathrm{n}$ & $\%$ & $\mathrm{n}$ & $\%$ \\
\hline Baik & 43 & 68,8 & 24 & 31,2 & 77 & 100 \\
\hline Kurang & 0 & 0 & 7 & 100,0 & 7 & 100 \\
\hline \multicolumn{7}{|c|}{$P$ value 0,000} \\
\hline
\end{tabular}

Berdasarkan tabel 2, terlihat bahwa komitmen dan kebijakan K3 yang baik memilikiproduktivitas baik yaitu sebanyak $53(68,8 \%)$, dan komitmen dan kebijakan K3 yang baik memilikiproduktivitas kurang yaitu sebanyak 24 (31,2\%). Sedangkan komitmen dan kebijakan K3 yang kurang memilikiproduktivitas baik yaitu sebanyak 0 $(, 0 \%)$, dan komitmen dan kebijakan K3 yang kurang memilikiproduktivitas kurang yaitu sebanyak 7 (100,0\%).

Hasil analisis statistik menunjukkan nilai probabilitas $(p=0,000)$, yang berarti jika nilai $(p=0,000)>\alpha 0,05$ dimana Ho diterima, maka ada hubungan antara komitmen dan kebijakan K3 denganproduktivitas kerja karyawan PT. Maruki Internasional Indonesia

Tabel 3 Hubungan Pelaksanaan K3 Dengan Produktivitas Kerja Karyawan PT. Maruki Internasional Indonesia

\begin{tabular}{|c|c|c|c|c|c|c|}
\hline \multirow{2}{*}{$\begin{array}{c}\text { Pelaksa } \\
\text { naan K3 }\end{array}$} & \multicolumn{4}{|c|}{ Produktivitas Kerja } & \multirow{2}{*}{ Total } \\
\cline { 2 - 6 } & \multicolumn{2}{|c|}{ Baik } & \multicolumn{2}{|c|}{ Kurang } & \\
\cline { 2 - 6 } & $\mathrm{n}$ & $\%$ & $\mathrm{n}$ & $\%$ & $\mathrm{n}$ & $\%$ \\
\hline Baik & 49 & 72,1 & 19 & 27,9 & 68 & 100 \\
\hline Kurang & 4 & 25,0 & 12 & 75,0 & 16 & 100 \\
\hline \multicolumn{6}{|c}{$p=0,000$} \\
\hline
\end{tabular}

Berdasarkan tabel 3, terlihat bahwa pelaksanaan K3 yang baik memilikiproduktivitas baik yaitu sebanyak $49(72,1 \%)$, dan pelaksanaan K3 yang baik memilikiproduktivitas kurang yaitu sebanyak 19 (27,9\%). Sedangkan pelaksanaan K3 yang kurang memilikiproduktivitas baik yaitu sebanyak 4 $(25,0 \%)$, dan pelaksanaan K3 yang kurang memilikiproduktivitas kurang yaitu sebanyak 12 (75,0\%).

Hasil analisis statistik menunjukkan nilai probabilitas $(p=0,000)$, yang berarti jika nilai $(p=0,000)>\alpha 0,05$ dimana Ho diterima, maka ada hubungan antara pelaksanaan K3 denganproduktivitas kerja karyawan PT. Maruki Internasional Indonesia.

3. Analisis Multivariat

Tabel 3 Pengaruh Komitmen dan Kebijakan K3, Pelaksanaan K3 Terhadap Produktivitas Kerja Karyawan PT. Maruki Internasional Indonesia

\begin{tabular}{|c|c|c|c|c|c|c|c|c|}
\hline \multirow[t]{2}{*}{ Variabel } & \multirow[t]{2}{*}{ B } & \multirow[t]{2}{*}{ S.E. } & \multirow[t]{2}{*}{ Wald } & \multirow[t]{2}{*}{$d f$} & \multirow[t]{2}{*}{ Sig } & \multirow[t]{2}{*}{$\begin{array}{l}\text { Exp } \\
\text { (B) }\end{array}$} & \multicolumn{2}{|c|}{$\begin{array}{l}95 \% \\
\text { C.I.for } \\
\text { EXP(B) }\end{array}$} \\
\hline & & & & & & & $\begin{array}{l}\text { Lo } \\
\text { wer }\end{array}$ & Jp pe \\
\hline \begin{tabular}{|c|}
$\begin{array}{c}\text { Komitmen } \\
\text { dan }\end{array}$ \\
Kebijakan K3
\end{tabular} & 21,420 & ,889 & ,000 & 1 & 999 & 2,007 & ,000 & \\
\hline $\begin{array}{c}\text { Pelaksanaan } \\
\text { K3 }\end{array}$ & 1,860 & 694 & 7,186 & 1 & , 007 & 6,424 & $\mid 1,649$ & $\begin{array}{l}25 \\
027\end{array}$ \\
\hline Constant & $-47,232$ & ,778 &, 000 & 1 & ,999 &, 000 & & \\
\hline
\end{tabular}

Berdasarkan analisis multivariat yang dilakukan dengan menggunakan uji regresi logistic, maka dapat dijelaskan bahwa variabel yang sangat signifikan atau yang mempunyai pengaruh kuat terhadap produktivitas kerja karyawan adalah pelaksanaan K3 dengan nilai sig. 0,007 dan nilai wald 7,18 . 


\section{PEMBAHASAN}

1. Hubungan Komitmen dan Kebijakan K3 Dengan Produktivitas Kerja Karyawan PT. Maruki Internasional Indonesia

Berdasarkan hasil penelitian yang diperoleh peneliti, bahwa komitmen dan kebijakan $\mathrm{K} 3$ berhubungan dengan produktivitas kerja karyawan PT. Maruki Internasional Indonesia.Dapat dilihat dari peraturan dan prosedur K3 tidaklah terlalu rumit sehingga mudah untuk dipahami, mudah diterapkan dengan benar, Diberlakukan sanksi jika ada pelanggaran dan perlu adanya perbaikan secara berkala.Pihak perusahaan juga memberikan beban kerja yang proporsional kepada karyawan.

Penelitian ini sejalan dengan penelitian yang dilakukan oleh Christina dkk (2012), Sebuah kebijakan K3 harus dimulai dari top management, diwujudkan dengan perhatian terhadap K3 dan perhatian terhadap tindakan-tindakan bahaya yang mengancam K3. Peraturan dan prosedur $\mathrm{K} 3$ yang mudah dimengerti, dimana dengan mensosialisasikan semua peraturan yang dibuat oleh manajemen mengenai masalah $\mathrm{K} 3$ dengan bahasa yang mudah dimengerti oleh para pekerja sehingga mempermudah pekerja untuk melaksanakan peraturan dan prosedur tersebut. Peraturan dan prosedur K3 sangat diperlukan, dimana para pekerja akan melakukan pekerjaannya dengan maksimal karena merasa terlindungi dengan adanya peraturan dan prosedur tersebut sehingga mampu meningkatkan produktivitas kerja karyawan.

Berdasarkan hasil penelitian yang dilakukan oleh Kusuma (2017), Peraturan keselamatan kerja yang selalu dilaksanakan oleh semua karyawan juga menjadi acuan penting bagi penerapan keselamatan kerja yang maksimal. Karyawan telah memiliki kesadaran akan pentingnya keselamatan dalam bekerja. Dengan mematuhi peraturan keselamatan kerja yang telah dibuat oleh perusahaan, maka produktivitas kerja karyawan akan meningkat karena resiko kecelakaan kerja maupun kerugian dapat ditekan.

Hasil penelitian Busyairi dkk (2014) mengemukakan bahwa perusahaan yang baik adalah perusahaan yang benar -benar menjaga keselamatan dan kesehatan karyawannya dengan membuat aturan tentang keselamatan dan kesehatan kerja yang dilaksanakan oleh seluruh karyawan dan pimpinan perusahaan.Perlindungan tenaga kerja dari bahaya dan penyakit akibat kerja atau akibat dari lingkungan kerja sangat dibutuhkan oleh karyawan agar karyawan merasa aman dan nyaman dalam menyelesaikan pekerjaannya. Tenaga kerja yang sehat akan bekerja produktif, sehingga diharapkan produktivitas kerja karyawan meningkat.

2. Hubungan Pelaksanaan K3 Dengan Produktivitas Kerja Karyawan PT. Maruki Internasional Indonesia

Berdasarkan hasil penelitian yang diperoleh peneliti, bahwa pelaksanaan K3 berhubungan dengan produktivitas kerja karyawan PT. Maruki Internasional Indonesia. Dapat dilihat dari pelaksanaan K3 yang dilakukan berupa sosialisasi halhal yang berkaitan dengan SMK3, seperti sosialisasi program K3, penggunaan APD, alat pemadam kebakaran, dan safety talksmempengaruhi tingkat produktivitas kerja karyawan. Pelaksanaan K3 yang diadakan perusahaan bertujuan untuk meningkatkan produktivitas karyawan dan melatih karyawan dalam menghindari terjadinya kecelakaan kerja dan melindungi diri apabila terjadi kecelakaan kerja.

Penelitian ini sejalan dengan penelitian yang dilakukan oleh Kusuma (2017).Keselamatan kerja yang ada di perusahaan telah dimaksimalkan penerapannya, baik sarana dan prasarana yang diberikan perusahaan guna menunjang keselamatan kerja karyawannya dan produktivitas kerja. Sarana dan prasarana penunjang K3 tersebut seperti APAR yang harus tersedia disetiap lantai gedung, safety helmet, safety shoes, ear plug, sarung tangan tangan, dan masker yang harus selalu dipakai pada saat melakukan pekerjaannya khususnya karyawan bagian lapangan.

Pemasangan rambu-rambu K3 seperti rambu-rambu tegangan tinggi, mudah terbakar, dan larangan merokok, dll. SOP K3 yang jelas, seperti SOP penggunaan perancah yang baik dan benar, cara penggunaan cheater yang benar. Pemasangan sign board K3 berupa slogan-slogan yang mengingatkan akan perlunya bekerja dengan selamat.

Berdasarkan penelitian yang dilakukan Busyairi dkk (2014). Perusahaan harus mengerti bahwa keselamatan kerja yang baik adalah dengan memberikan karyawan alat pelindung diri, memperhatikan kondisi alat kerja, melakukan perawatan alat, menyediakan bahan baku yang baik, memberikan penerangan/pencahayaan yang baik di lokasi kerja, serta kebersihan dan 
ketertiban yang terjaga. Jika perusahaan dapat memenuhi hal- hal tersebut maka karyawan akan bekerja dengan lebih nyaman tanpa ada rasa khawatir akan terjadi kecelakaan kerja, sehingga karyawan lebih produktif lagi dalam bekerja.

\section{KESIMPULAN}

1. Ada hubungan komitmen dan kebijakan K3 dengan produktivitas kerja karyawan PT. Maruki Internasional Indonesia

2. Ada hubungan pelaksanaan K3 dengan produktivitas kerja karyawan PT. Maruki Internasional Indonesia

\section{SARAN}

1. Diharapkan pihak perusahaan PT. Maruki Internasional Indonesia meningkatkan pelaksanaan K3 di tempat kerja untuk meningkatkan produktivitas kerja karyawan.

2. Diharapkan pihak perusahaan PT. Maruki Internasional Indonesia meningkatkan komitmen dan kebijakan K3 untuk meningkatkan produktivitas kerja karyawan

3. Diharapkan pihak perusahaan PT. Maruki Internasional Indonesia meningkatkan pelaksanaan K3 untuk meningkatkan produktivitas karyawan.

\section{DAFTAR PUSTAKA}

Busyairi, M., Tosungku, L. O. A. S., \& Oktaviani, A. (2014). Pengaruh Keselamatan dan Kesehatan Kerja Terhadap Produktivitas Karyawan. Jurnal IImiah Teknik Industri, 13(2), 112-124. https://doi.org/10.23917/jiti.v16i1.3862

Korry Apriandi , Evi Widowati S.KM, M. K. (2014). Pelaksanaan Sistem Manajemen Keselamatan Dan Kesehatan Kerja (Smk3) Berdasarkan Ohsas 1800: 2007 Pada Unit Spinning V Pt. Sinar Pantja Djaja (Pt. Spd) Di Semarang Tahun 2014. Unnes Journal of Public Health, 3(1), 1-9

Ramli, S. (2010) Sistem Manajemen Keselamatan dan Kesehatan Kerja. Jakarta: PT. Dian Rakyat

Ramli, S. (2013) Smart Safety Panduan SMK3 Yang Efektif. Jakarta: PT. Dian Rakyat. 